\title{
NEIGHBOURHOOD INFECTIONS OF CLASSICAL SWINE FEVER DURING THE 1997-1998 EPIDEMIC IN THE NETHERLANDS
}

\author{
A.P.P. Crauwels ${ }^{1,2}$, M. Nielen', A.R.W. Elbers ${ }^{2}$, J.A. Stegeman", M.J.M. Tielen ${ }^{2,3}$ \\ 'Farm Management Group, Wageningen University, Hollandseweg 1, 6706 KN Wageningen, \\ The Netherlands \\ 'Animal Health Service, Deventer, the Netherlands \\ ${ }^{3}$ Department of Farm Animal Health, Faculty of Veterinary Medicine, University Utrecht, \\ The Netherlands.
}

\begin{abstract}
The objective of this study was to identify risk factors for classical swine fever infections (CSF) that influenced the infection rate of neighbour herds during the infectious period of the neighbourhood. The analyses were based on data collected during the 1997-1998 CSF-epidemic in the Netherlands. Serological findings at depopulation were used to estimate the date the virus was introduced into the source or neighbour herd. Univariable and multivariable survival analysis were used to identify factors that influenced the infection rate of neighbour herds.

The analyses show that the infection rate increases with increasing herd size of both the source herd and the neighbour herd. Breeding herds and mixed herds show a 2.2 times higher infection rate then for finishing herds. Furthermore, the infection rate decreases by increasing distance from the source herd and with time down wind. The latter is an unexpected result, which cannot be explained yet. Finally, the results indicate that preventive slaughter was an effective control measure to decrease the infection rate.
\end{abstract}

\section{INTRODUCTION}

During recent epidemics of classical swine fever (CSF) in Belgium, Germany, and the Netherlands, it was observed that secondary outbreaks of CSF frequently occurred in close vicinity to primary outbreaks of CSF (Koenen et al., 1996, Kramer et al., 1995; Pluimers et al., 1999; Roberts, 1995; Vanthemsche, 1996). Such secondary outbreaks were classified as neighbourhood infections if (i) they occurred within $1000 \mathrm{~m}$ of the primary outbreak; (ii) the estimated date of virus introduction in the herd was within the infectious period of the primary outbreak, and; (iii) if there were no indications for other infection routes (Elbers et al., 1999). The mechanisms underlying these neighbourhood infections are still poorly understood.

Infection routes suggested as potential modes of virus transmission between neighbouring herds include airborne spread over short distances (<25 meters) (Falk and Hunt, 1980; Hughes and Gustafson, 1960; Laevens et al., 1998; Laevens et al., 1999; Roberts, 1995; Terpstra, 1987), spread by pet animals (Miry et al., 1991), rodents (Westergaard, 1996), birds (Hughes and Gustafson, 1960), and insects (Morgan and Millar, 1976). Other possible routes of virus transmission are unreported contacts between neighbourhood farms (Elbers et al., 2001). Airborne transmission of CSF virus over short distances was experimentally demonstrated by Dewulf (2000), Hughes and Gustafson (1960) and Terpstra (1987). However, the attempt to isolate CSF virus from the air of rooms housing experimentally infected pigs has not been successful (Stärk, 1998). In all, although none of these authors actually established the relation between the distance to the source of virus and the probability of infection, airbome transmission of CSF virus was expected to be of importance only for very short distances. Spread by pet animals, birds or insects was never established. 
A possible strategy to control neighbourhood infections is preventive depopulation of herds near a primary outbreak (Elbers et al.,1998). In this control strategy, all pigs in herds near the primary outbreak are killed and destroyed, even if no clinical signs of the disease are seen at that moment, to (i) reduce the infectivity of possibly infected neighbouring herds by reducing the length of the infectious period to zero and by reducing the number of infectious pigs in infected herds; (ii) to decrease the density of herds with susceptible pigs, which results in a decrease of the contact rate and the number of different herds that can be contacted (Elbers et al., 1999). Local preventive depopulation as a control strategy was used in the European Union (EU) in CSF epidemics in Belgium, Germany, and the Netherlands. In all three countries, herds within a radial distance of $1000 \mathrm{~m}$ of an infected herd were preventively depopulated (Elbers et al., 1998; Pluimers et al., 1999; Roberts, 1995; Staubach et al., 1997; Vanthemsche, 1996). However, depending on the radius of preventive depopulation, and the number of herds and pigs within that radius, the costs of this control strategy can be prohibitive. In addition, preventive depopulation may need more destruction capacity and labour than available and the killing and destroying of healthy pigs raises ethical questions. To determine the best control strategy with respect to epidemiological results and economic losses a better understanding of neighbourhood infections is necessary.

This study attempts to improve the understanding of neighbourhood infections by analysing the occurrence of neighbourhood infections during the 1997-1998 epidemic in the Netherlands. Survival analysis (Cox proportional hazard regression) was used to identify risk factors that influenced the date of virus introduction into neighbouring herds during the infectious period of the neighbourhood.

\section{MATERIALS AND METHODS}

\subsection{Study population}

The study population consisted of all herds in the neighbourhood of CSF infected herds during the 1997-1998 epidemic of CSF in the Netherlands. A neighbourhood was defined as an area with a radius of $1000 \mathrm{~m}$ around an outbreak (source herd). Cases were herds that became infected within the infectious period of the neighbourhood they belonged to.

Serological findings at depopulation were used to estimate the weekly probabilities the virus was introduced into the source or neighbourhood herd (Stegeman et al., 1999). From the distribution of all possible weeks of virus introduction into the herd, one week was drawn weighted to the weekly cumulative probabilities. Next, within this week one day was randomly drawn to serve as the estimated date of vinus introduction of the herd. Because it takes 4-6 days before animals start to excrete the virus we assumed that herds became infectious for other herds one week after the estimated introduction of the vins into the herd (Stegeman et al., 1999). Subsequently, the defined infectious period ended at the date of depopulation of the herd. Infected herds for which no date of virus introduction could be estimated were excluded.

The randomisation process to estimate the infection date of all herds was executed ten times resulting in ten different data sets. These data sets were used to check how sensitive the results were for the randomly estimated infection dates. Results of one of the data sets will be presented.

Dates of depopulation of infected herds, dates of preventive depopulation of neighbouring herds and serological findings at depopulation were obtained from the CSF database of the National Inspection Service for Livestock and Meat (RVV). The RVV also provided information to determine per neighbourhood the date of onset of the buy-out programme from overstocked herds.

\subsection{Risk factors}

The risk factors investigated in this study are listed and explained in Table 1. Herd size, herd type and presence of other production animals were analysed for both the source herd and the neighbouring herd.

In the course of the epidemic the transportation ban and the implemented programme for buying-out pigs from overstocked herds affected the actual herd size. The latter was of special importance for finishing- and rearing herds because due to these measures the herd size of these herds decreased with time. Therefore, we decreased the herd size from the moment the buying-out programme was started with $20 \%$ per month for finishing and 
rearing herds. As a result, four months after the start of a buying-out programme in a neighbourhood a finishingor rearing herd was defined empty. Herd size was calculated for all herds by summing up sows, replacement sows, and finishing pigs after correction for the buying-out programme.

Table 1. Investigated risk factors in this study.

- Herd size:

Based on number of sows, replacement sows, and finishing pigs as available from the Herd Registration Database of the Animal Health Service prior to the epidemic.

Categories: $<250 ; 250-750 ;>750$.

- Production type: Based on the number of sows, replacement sows, and finishing pigs. If no sows were present, the production type of the herd was declared a finishing herd. If the number of sows was greater then the number of replacement sows plus the number of finishing pigs, the herd was declared a breeding herd. All other herds were declared mixed herds.

Categories: finishing herd; breeding herd; mixed herd.

- Presence of other The presence of other production animals (poultry or cattle) was derived from production animals: the Herd Registration Database of the Animal Health Service in the Netherlands. No reliable information on the presence or absence of sheep or goats was available.

Categories: no other production animals present; cattle present; poultry present; cattle and poultry present.

- Same street: Being situated in the same street as the source herd.

Categories: yes / no

- Radial distance

Radial distance between the source herd and the neighbouring herd. Radial distance was analysed as a class variable.

Categories: $0-250 \mathrm{~m} ; 250-500 \mathrm{~m} ; 500-750 \mathrm{~m} ; 750-1000 \mathrm{~m}$.

- Implementation stage of In the first stage of the epidemic, no pre-emptive slaughter was applied (stage preventive slaughter:

1). From 20 April 1997 on pre-emptive slaughter was applied but came not into full effect (stage 2). Finally, from 15 June 1997 on pre-emptive slaughter came into full operation (stage 3). Neighbourhoods were assigned to a stage, based on the end date of the infectious period of that neighbourhood.

Categories: stage 1; stage 2; stage 3.

- Cumulative time of Hourly observations of wind direction during the period of 1 December 1996 being downwind from the to 31 March 1998 were obtained from the Royal Dutch Meteorological source herd during the Institute (KNMI) based on a weather observation station situated close to the infectious period: epidemic area. The hourly observations of wind direction were used to calculate the cumulative time a herd was down wind from the infected source herd during the entire infectious period. A herd was considered to be down wind if the herd was located within the compass triangle formed by wind direction plus or minus $5^{\circ}$.

Categories: $0 \mathrm{~h} ; 1-5 \mathrm{~h} ; 5-10 \mathrm{~h} ; 10-20 \mathrm{~h} ;>20 \mathrm{~h}$.

- Length of the infectious Time (in weeks) between the estimated day the source herd became infectious period of the source herd:

and the day of depopulation of that source herd.

Categories: 1 week; 2 weeks; 3 weeks; $>3$ weeks.

\subsection{Statistical analyses}

Univariable and multivariable survival analysis were used to identify factors that influenced the infection rate of neighbour herds during the infectious period of the neighbourhood. A neighbour herd was defined as a case in a particular neighbourhood if the estimated date of virus introduction of that herd was within the infectious period of the source herd. Neighbour herds that never became infected were right-censored at the last date of the infectious period of the source herd. Neighbouring herds that became empty within the infectious period or within the following 21 days due to preventive depopulation or due to the implemented buying-out programme were right-censored 21 days before the moment of becoming empty. This was done as a correction for the time a herd could be infected without being noticed as such. In the analysis in which neighbour herds were randomly assigned to just one neighbourhood, cases were right-censored at their estimated date of virus introduction in all other neighbourhoods they were part of, thus did not become case in those other neighbourhoods. 
Kaplan-Meier (LIFETEST procedure in SAS, Release 6.12; SAS Institute) was used to evaluate the effect each stratum of a risk factor had on the infection rate of a neighbour herd. Kaplan-Meier survival curves for each stratum of a risk factor were plotted. The log rank test and the Wilcoxon (Breslow) test were used to test the homogeneity of the curves between strata. Risk factors that were associated with the infection rate $(a t \quad P<0.20)$ were selected for the multivariable analysis.

To assess the proportional hazards assumption a test of trend in the hazard ratio was performed for each factor by testing a time-dependent explanatory variable $x=x(t)$, representing the interaction of the explanatory variable with the time at risk. A nonzero value of the regression parameter for the time-dependent variable $\mathbf{x}$ implies a trend in the hazard ratio with time (Wald's $X^{2}, p \leq 0.10$ ). If so, the time-dependent variable $\mathrm{x}$ was included in the final model (SAS Institute, Inc., 1997). The survivorship function $S(t)$ for each stratum of an associated risk factor was also plotted as $\log [-\log S(t)]$ against $\ln (t)$ as a visual assessment of the proportional hazard assumption.

Factors that were univariable associated with the survival time of a neighbouring herd $(P<0.20)$ were included in a multivariable Cox proportional hazards model (PHREG procedure in SAS Release 6.12) by using an in hand elimination procedure. The significance of explanatory variables to the model was tested by using a likelihood ratio test $(P<0.01)$.

Separate multivariable models were built for risk factors related to the source herd, risk factors related to the neighbour herd and risk factors not specifically related to herds. Finally, all significant tested factors from the separate multivariable models were tested in a full multivariable model (likelihood ratio test $(\mathrm{P}<0.01)$ ).

\section{RESULTS}

The randomisation process to estimate the infection date of a herd appeared to be of minor influence on the parameter estimates in the proportional hazard models. Only small differences occurred in the levels of the estimated hazard rates (HR) and opposite results were not found.

From the univariable analysis of source herd related risk factors production type and herd size appeared to be related to the hazard for neighbour herds to become infected. No statistical differences were found in the parameter estimates of the production types 'breeding herd' and 'mixed herd'. Therefore, in the multivariable analyses these production types were combined resulting in the two production types finishing herds and all other herds. Also no statistical differences were found in the parameter estimates for herd size 250-750 and $>750$. These two categories were combined. The results of the multivariable Cox proportional hazards model for source herd related risk factors are shown in Table 2.

Table 2. Multivariable Cox proportional hazard regression model showing the effect of the source herd related variables production type and herd size on the hazard to become infected.

\begin{tabular}{|c|c|c|c|c|c|}
\hline $\begin{array}{l}\text { Explanatory } \\
\text { variable }\end{array}$ & $\begin{array}{l}\# \text { Of herds } \\
\text { at risk }\end{array}$ & $\begin{array}{l}\# \text { Of infected } \\
\text { neighbour herds }\end{array}$ & $\begin{array}{l}\text { Regression } \\
\text { coefficient (se) }\end{array}$ & Hazard ratio & $\begin{array}{l}95 \% \text { CI of } \\
\text { hazard ratio }\end{array}$ \\
\hline \multicolumn{6}{|l|}{ Production type } \\
\hline Finishing herd & 659 & 68 & $0.4107(0.1430)$ & 1.51 & $1.14-2.00$ \\
\hline Others & 2248 & 205 & & 1.00 & \\
\hline \multicolumn{6}{|l|}{ Herd size } \\
\hline$\leq 250$ & 879 & 64 & & 1.00 & \\
\hline$>250$ & 2028 & 209 & $0.3942(0.1445)$ & 1.48 & $1.12-1.97$ \\
\hline
\end{tabular}

If the source herd was a finishing herd the infection rate was 1.51 times higher than if the source herd was not a finishing herd. The infection rate for a neighbour herd increased with increasing herd size of the source herd. 
In the univariable analyses the neighbour herd related risk factors production type and herd size were related to the hazard to become infected. The same regrouping as for source herds was performed based on similar statistical results.

Over the ten data sets there was a tendency in the univariable analysis that the presence of cattle at the neighbour herd was also related to a reduced hazard for neighbour herds to become infected $(\mathrm{HR}<1)$. However, in the multivariable analysis this variable almost never reached the significance of inclusion $(p<0.01)$ in the final model. The results of the multivariable Cox proportional hazards model for neighbour herd related risk factors are shown in Table 3. If the neighbour herd was not a finishing herd the infection rate increased by 2.10 . The infection rate of a neighbour herd increased by increasing herd size.

Table 3. Multivariable Cox proportional hazard regression model showing the effect of the neighbour herd related variables production type and herd size on the hazard to become infected.

\begin{tabular}{|c|c|c|c|c|c|}
\hline $\begin{array}{l}\text { Explanatory } \\
\text { variable }\end{array}$ & $\begin{array}{l}\# \text { Of herds } \\
\text { at risk }\end{array}$ & $\begin{array}{l}\# \text { Of infected } \\
\text { neighbour herds }\end{array}$ & $\begin{array}{l}\text { Regression } \\
\text { coefficient (se) }\end{array}$ & Hazard ratio & $\begin{array}{l}95 \% \text { Cl of } \\
\text { hazard ratio }\end{array}$ \\
\hline \multicolumn{6}{|l|}{ Production type } \\
\hline Finishing herd & $15 ! 2$ & 84 & & 1.00 & \\
\hline Other & 1395 & 189 & $0.7411(0.1357)$ & 2.10 & $1.61-2.70$ \\
\hline \multicolumn{6}{|l|}{ Herd size } \\
\hline$\leq 250$ & 1545 & 90 & & 1.00 & $0.39-0.66$ \\
\hline$>250$ & 1362 & 183 & $0.6746(0.1330)$ & 1.96 & $1.52-2.56$ \\
\hline
\end{tabular}

From the risk factors not specifically related to herds the factors neighbour herd in the same street as source herd, radial distance, time down wind and stage of preventive slaughter appeared to be related in the univariable analysis to the hazard for neighbour herds to become infected. The category $250-500 \mathrm{~m}$ of the risk factor radial distance differed not significantly from the category $250-500 \mathrm{~m}$ and the category $500-750 \mathrm{~m}$ differed not significantly from the category $750-1000 \mathrm{~m}$. Therefore, the risk factor was recoded in the categories $0-500 \mathrm{~m}$ and $500-1000 \mathrm{~m}$. In the third stage of implementing preventive slaughter (after 15 June '97) almost no neighbourhood infections occurred. Therefore, this stage was joined together with the second stage.

Table 4. Multivariable Cox proportional hazard regression model showing the effect of various variables on the hazard to become infected.

\begin{tabular}{|c|c|c|c|c|c|}
\hline $\begin{array}{l}\text { Explanatory } \\
\text { variable }\end{array}$ & $\begin{array}{l}\text { \# Of herds } \\
\text { at risk }\end{array}$ & $\begin{array}{l}\# \text { Of infected } \\
\text { neighbour herds }\end{array}$ & $\begin{array}{l}\text { Regression } \\
\text { coefficient (se) }\end{array}$ & Hazard ratio & $\begin{array}{l}95 \% \quad \mathrm{CI} \text { of } \\
\text { hazard ratio }\end{array}$ \\
\hline \multicolumn{6}{|l|}{ Same street } \\
\hline No & 2261 & 193 & & 1.00 & \\
\hline Yes & 646 & 80 & $0.2433(0.1438)$ & 1.28 & $0.96-1.69$ \\
\hline \multicolumn{6}{|l|}{ Radial distance } \\
\hline $0-500 \mathrm{~m}$ & 897 & 110 & & 1.00 & \\
\hline $500-1000 \mathrm{~m}$ & 2010 & 163 & $-0.3577(0.1332)$ & 0.70 & $0.54-0.91$ \\
\hline \multicolumn{6}{|l|}{ Time down wind } \\
\hline $0 \mathrm{~h}$ & 263 & 45 & & 1.00 & \\
\hline $1-5 h$ & 794 & 97 & $-0.8873(0.1838)$ & 0.38 & $0.29-0.59$ \\
\hline $5-10 h$ & 668 & 61 & $-1.6834(0.2055)$ & 0.17 & $0.12-0.28$ \\
\hline $10-20 \mathrm{~h}$ & 656 & 38 & $-2.4534(0.2341)$ & 0.09 & $0.05-0.14$ \\
\hline$>20 \mathrm{~h}$ & 526 & 32 & $-2.7546(0.2514)$ & 0.06 & $0.04-0.10$ \\
\hline \multicolumn{6}{|c|}{$\begin{array}{l}\text { Stage preventive } \\
\text { slaughter }\end{array}$} \\
\hline$\leq 20$ April $' 97$ & 1467 & 194 & & 1.00 & \\
\hline$>20$ April ' 97 & 1440 & 79 & $-0.6379(0.1358)$ & 0.53 & $0.41-0.69$ \\
\hline
\end{tabular}


The results of the multivariable Cox proportional hazards model for risk factors not specifically related to herds are shown in Table 4. The infection rate of a herd being situated in the same street as a source herd was 1.28 times higher than of a herd not situated in the same street as a source herd. The infection rate of a herd located more than $500 \mathrm{~m}$ from a source herd was 0.70 times lower than of a herd located within $500 \mathrm{~m}$ of a source herd. The longer a herd was down wind from a source herd the more the infection rate decreased. After 20 April ' 97 the infection rate of a neighbour herd was 0.53 times lower than before 20 April ' 97 .

The results of the final multivariable Cox proportional hazard regression model are shown in Table 5. The production type of the source herd and being situated in the same street as the source herd dropped from the final model. All other factors remained significant in the final model.

Table 5. Multivariable Cox proportional hazard regression model showing the effect of all factors on the hazard for neighbour herds to become infected.

\begin{tabular}{|c|c|c|c|c|c|}
\hline $\begin{array}{l}\text { Explanatory } \\
\text { variable }\end{array}$ & $\begin{array}{l}\# \text { Of herds } \\
\text { at risk }\end{array}$ & $\begin{array}{l}\# \quad \text { Of infected } \\
\text { neighbour herds }\end{array}$ & $\begin{array}{l}\text { Regression } \\
\text { coefficient (se) }\end{array}$ & Hazard ratio & $\begin{array}{l}95 \% \text { CI of } \\
\text { hazard ratio }\end{array}$ \\
\hline \multicolumn{6}{|l|}{$\begin{array}{l}\text { Source herd } \\
\text { Herd size }\end{array}$} \\
\hline$\leq 250$ & 879 & 64 & & 1.00 & \\
\hline$>250$ & 905 & 96 & $0.3399(0.1445)$ & 1.40 & $1.06-1.87$ \\
\hline \multicolumn{6}{|l|}{ Neighbour herd } \\
\hline \multicolumn{6}{|l|}{ Production type } \\
\hline Finishing herd & 1512 & 84 & & 1.00 & $0.35-0.59$ \\
\hline Other & 1395 & 189 & $0.77887(0.1351)$ & 2.22 & $1.69-2.86$ \\
\hline \multicolumn{6}{|l|}{ Herd size } \\
\hline$\leq 250$ & 1545 & 90 & & 1.00 & $0.39-0.66$ \\
\hline$>250$ & 1362 & 183 & $0.5068(0.1339)$ & 1.66 & $1.28-2.16$ \\
\hline \multicolumn{6}{|l|}{ Others } \\
\hline \multicolumn{6}{|l|}{ Radial distance } \\
\hline $0-500 \mathrm{~m}$ & 897 & 110 & & 1.00 & \\
\hline $500-1000 \mathrm{~m}$ & 2010 & 163 & $-0.4293(0.1238)$ & 0.65 & $0.51-0.83$ \\
\hline \multicolumn{6}{|l|}{ Time down wind } \\
\hline $0 \mathrm{~h}$ & 263 & 45 & & 1.00 & \\
\hline $1-5 h$ & 794 & 97 & $-0.9300(0.1850)$ & 0.40 & $0.28-0.57$ \\
\hline $5-10 \mathrm{~h}$ & 668 & 61 & $-1.7208(0.2071)$ & 0.18 & $0.12-0.27$ \\
\hline $10-20 h$ & 656 & 38 & $-2.4370(0.2355)$ & 0.09 & $0.06-0.14$ \\
\hline$>20 \mathrm{~h}$ & 526 & 32 & $-2.7883(0.2525)$ & 0.06 & $0.04-0.10$ \\
\hline \multicolumn{6}{|c|}{$\begin{array}{l}\text { Stage preventive } \\
\text { slaughter }\end{array}$} \\
\hline$\leq 20$ April $\bullet 97$ & 1467 & 194 & & 1.00 & \\
\hline$>20$ April ' 97 & 1440 & 79 & $-0.5074(0.1376)$ & 0.60 & $0.46-0.78$ \\
\hline
\end{tabular}

\section{DISCUSSION}

be presented and discussed at the ISVEE.

The following discussion points will be presented and discussed at the VEEC-presentation:

- Data quality and limitations

- Consideration of the results with respect to previous investigations

- Explanation and relevance of the results with respect to contemporary knowledge

- Possible consequences of the findings for handling future CSF-epidemics 


\section{ACKNOWLEDGEMENTS}

The authors acknowledge the Technology Foundation (STW) in Utrecht, The Netherlands for funding the research. The authors also would like to thank Charles Leon for preparing parts of the data sets.

\section{REFERENCES}

Dewulf, J., Laevens, H., Koenen, F., Mintiens, K., and De Kruif, A. Airborne transmission of classical swine fever virus is possible under experimental conditions. "In: Proc. of the IXth Symposium of the International Society for Veterinary Epidemiology and Economics". ISVEE, Breckenridge, USA, 2000, pp. 715-717.

Elbers, A.R., Stegeman, A., Moser, H., De Jong, M.C.M., Ekker, H. M., Smak, J.A., and De Leeuw, P.W. Effectiviness of preventive culling of pig herds during the Dutch CSF epidemic. "In: Proc. of the 15th IPVS Congress, Birmingham, UK, 5-9 July 1998". IPVS, 1998, p. 271.

Elbers, A.R., Stegeman, A., Moser, H., Ekker, H.M., Smak, J.A., and Pluimers, F.H. The classical swine fever epidemic 1997-1998 in The Netherlands: descriptive epidemiology. Prev Vet Med 1999; 42: 157-184.

Elbers, A.R.W., Moser, H., Ekker, H.M., Crauwels, A.P.P., Stegeman, J.A., Smak, J.A., and Pluimers, F.H. Tracing systems used during the 1997-1998 classical swine fever epidemic in The Netherlands: a case study. Rev Sci Tech Off Int Epiz 2001; 20: 614-629.

Hughes, R.W., and Gustafson, D.P. Some factors that may influence hog cholera transmission. Am J Vet Res $1960 ; 21: 462-471$.

Koenen, F., Van Caenegem, G., Vermeersch, J.P., Vandenheede, J., and Deluyker, H. Epidemiological characteristics of an outbreak of classical swine fever in an area of high pig density. Vet Rec 1996; 139: 367-371.

Kramer, M., Ahl, R., Teuffert, J., Kroschewski, K., Schlüter, H., and Otte, J. Classical swine fever in Germany some epidemiological aspects. "In: Proceedings of the Society for Veterinary Epidemiology and Preventive Medicine". SVPEM, Reading, UK, 1995, pp. 110-118.

Laevens, H., Koenen, F., Deluyker, H., and De Kruif, A. An experimental infection with classical swine fever vinus in weaner pigs. I. Transmission of the virus, course of the disease, and antibody response. Vet Quart 1998; 20: 41-45.

Laevens, H., Koenen, F., Deluyker, H., and De Kruif, A. Experimental infection of slaughter pigs with classical swine fever virus: transmission of the virus, course of the disease and antibody response. Vet Rec 1999; 145: 243-248.

Mintiens, K., Laevens, H., Deluyker, H., Dewulf, J., Koenen, F., and De Kruif, A. Estimation of the likelihood for neighbourhood infections during the classical swine fever epidemics based on a spatial risk assesment of real outbreak data. "In: Proc. of the IXth Symposium of the International Society for Veterinary Epidemiology and Economics". ISVEE, Breckenridge, USA, 2000, pp. $712-713$.

Miry, C., Castryck, F., Koenen, F., Broers. A., and Segers, E. Some aspects of the classical swine fever epidemic in Belgium in 1990. Epidemiol Santé Anim 1976; 20: 23-32. (in French)

Morgan, N.O., and Miller, L.D. Muscidae (Diptera):experimental vectors of hog cholera vinus. J Med Entomol $1976 ; 12: 657-660$.

Pluimers, F.H., de Leeuw, P.W., Smak, J.A., Elbers, A.R., and Stegeman, J.A. Classical swine fever in The Netherlands 1997-1998: a description of organisation and measures to eradicate the disease. Prev Vet Med 1999; 42: 139-155.

Roberts, M. Evaluation of optimal size of restriction zones in disease control with particular reference to classical swine fever. "In: Proceedings of the Society for Veterinary Epidemiology and Preventive Medicine". Ed. Thrusfield, M.V., and Goodall, E.A. SVEPM, Reading, UK, 1995, pp. 119-130.

Stärk, K.D.C. Failure to isolate classical swine fever virus from the air of rooms housing experimentally infected pigs. "In: Systems for the prevention and control of infectious diseases in pigs". Ph.D. Thesis, ch. 2.2 . Massey University, Palmerston North, New Zealand, 1998, pp. 169-176.

Staubach, C., Teuffert, J., and Thulke, H.H. Risk analysis and local spread mechanisms of classical swine fever. Epidemiol Santé Anim, Paris France, 06.12.1-06.12.3, 1997.

Stegeman, A., Elbers, A.R., Smak, J., and De Jong, M.C.M. Quantification of the transmission of classical swine fever virus between herds during the 1997-1998 epidemic in The Netherlands. Prev Vet Med 1999a; 42: 219-234. 
Stegeman, A., Elbers, A.R., Bouma, A., de Smit, H., and De Jong, M.C.M. Transmission of classical swine fever virus within herds during the 1997-1998 epidemic in The Netherlands. Prev Vet Med 1999b; 42: 201218.

Terpstra, C.Epizootiology of swine fever. Vet Quart 1987; 9, suppl. 1: 50S-60S.

Vanthemsche, P. Classical swine fever 1993-1994 Belgium. Pig J 1996; 37: 43-53.

Westergaard, J.M. Epidemiology of classical swine fever. "In: Proceedings of the workshop on diagnosic procedures and measures to control classical swine fever in domestic pigs and the European wild boar". Ed.Truszczynski M. Pulawy Poland, 1996, pp. 119-130. 